\title{
Optimization of Plastics Injection Molding Process using Response surface Methodology
}

\author{
Sreedharan.J and A.K Jeevanantham \\ Department of Manufacturing Engineering, School of Mechanical Engineering, \\ VIT University, Vellore - 632 014, India
}

\begin{abstract}
This work is done in order to get the optimized process setting for an ABS Molded part which is molded in ABS, LG MP 220 Grade materials for an automotive requirement which is plated. The specimen sample is made in injection molding machine and we have used Response Surface Methodology, We have tried to optimize the process by picking 4 important process parameter which are variable in the molding machine which are Injection Time(IT),Holding Time(HT),Refilling time and the Mold closing Time(MCT) and these are taken to get an output which is Cycle time and it has been evaluated through an ANOVA table to understand the effect of Cycle time based on varying the parameters which gives us an ideal setting of the parameters for an Ideal cycle time based on the experiments.
\end{abstract}

Keywords: Acrylic Butadiene Styrene (ABS); Injection Time; Mold closing Time,; Response Surface Methodology; Shrinkage, Warpage

\section{INTRODUCTION}

This study is meant to predict molding defects and its effects in injection-molded thermoplastics components. We have used individual factors in injection molding parameters; this was tried using response surface methodology. Experiments were conducted with variables such as pressure and speed which influences and controls the injection molding process. These were selected and experiments carried out using Fractional factorial design (FFD) of experiments. Flow simulation to predict the flow of plastics material in the mold was done using mold flow analysis. The mold flow analysis can guide us in identifying the molding defect area and its intensity. The material used is ABS (Acrylic Butadiene Styrene)and it's characteristic is shown in Table 1, this study, is done systematically and carried out on the Response Surface Methodology (RSM) to identify the effects of factors in the molding and their behavior and their effects on shrinkage and warpage.

This analysis can help us on the process setting and the various parameters which can help prevent /reduce the molding defects on the molded plastic component. The practical results can help in ensuring the repeatability and the quality of the molded components. RSM is a convincing tactic for finding the link amongst a number of processing parameters and its performance with a number of defined standards and confirms the acceptance of these processing.

This paper deals with effects of shrinkage and warpage on a plastic molded component. Response surface methodology is used to understand and compare molding parameters against the design parameters. This is done in order to reduce the shrinkage and warpage on the molded components. In this we have considered the design characteristic of a specimen mold which was developed to understand the warpage and shrinkage. Mold flow analysis was done on the specimen part which was taken for a study.

The RSM is a strategy to achieve this goal that involves experimentation, data analysis, modeling and optimization. RSM is used to improve approximation for response variable. The main aim of the study is to understand the process parameters are close to design parameters. Plastics molding components have 2 important Manufacturing products have two most significant glitches which is optimization and process modeling. There are process parameters which are interlinked each other. Nowadays injection molding has become one of the most used process globally for molding intricate components.

Response Surface Methodology is used to combine statistical and experimental methods with data-fitting techniques. Regression analysis is done on the responses amid variables got from conducting experiments to ascertain the mathematical model which pleases the Connection of group of test factors and the objective functions it is used in This model is then used to discover the optimal solution in the experimental area [31][32]. Since RSM Techniques are practicable and very easy to implement and also we get a satisfactory results it is used in various industries.

Literature review on injection molding, design of experiment and Response surface methodology in injection molding: 
Sokkalingam Rajalingam [2] has worked on the Optimization of Injection Molding Process Parameters by Response Surface Methods in this study the authors have used RSM to optimize the quality characteristics by determining the most appropriate and accurate molding process parameters setting. Bano et al [1] has used RSM in injection molding and he has taken mold temperature, injection and refilling speed and these parameters have been found to reduce the rejection levels.S. M. Nasir, K. A. Ismail, and Z. Shayful [3] they have studied emphases on the analysis of plastic injection moulding process and it is simulated by using Autodesk Moldflow Insight (AMI) software the authors have tried to reduce shrinkage by optimizing the process parameters here 2 types of gates which is single and dual gates have been analyzed in this study.

Yung-Tsan Jou, Wen-Tsann Lin, Wei-Cheng Lee and Tsu-Ming Yeh,[4] Appl. Math. Inf. Sci. 8, No. 3, 12771285 (2014) the authors have chosen 6 key factors to analyze the process to form optical fiber cable which involves melting of plastics by integrating taguchi with Response surface methodogy.Ko-Ta Chiang \& Fu-Ping Chang[5] the study adopts the centered central composite design and it is made to fit the quadratic model of the response surface methodology. The factorial part of CCD is complete factorial design with factors at 2 levels with possible combinations.

Chih-Cherng Chen \& Pao-Lin Su \& Yan-Cherng Lin[6],a systematic approach on response surface methodology using design of experiments on the process parameters to study the effect of shrinkage variations of a thin shell part this study works on the way to reduce the shrinkage variation in order to produce better quality of molded part.Ozcelik and Erzumlu [7] have worked on the ways to find and minimize the warpage on thin shell plastic parts by using Response surface Methodology with genetic algorithm. Kurtaran et. al [8] has worked on finding the ideal values of process parameters which are mold temperature, melt temperature, packing pressure, packing pressure time and cooling time, which is used in molding of a bus ceiling lamp base he has used different techniques to accomplish minimum warpage using the finite element software, Mold Flow, statistical design of experiments, artificial neural network and genetic algorithm. The shrinkage and warpage always considered as the lower-the-better performance characteristics in an injection-molded part with a thin-shell feature. Jansen et al. [9] explored the outcome of processing conditions on shrinkage in the injection molding process and he has used 7different types of plastic material which includes PC, PS, ABS and HIPS which are amorphous thermoplastic and PBT, PBT plus 30\% glass filled which are semi crystalline materials and HDPE have chosen in this study. These materials are processed by varying the packing pressure, injection velocity, melt and mold wall temperatures. Here they have identified increase in holding pressure and melt temperature will decrease the shrinkage on the molded part and also one more finding is adding the short glass fibre will reduce the shrinkage up to $0.2 \%$ Long et al. [10] has studied the effect of molding parameters in plastic bra-cups where the optimum settings is found by analyzing the main and interaction effects by RSM to obtain the required response. Mathivanan et al. [11] worked on a nonlinear model to find out the optimum parameters in molding using RSM. Chuang et al. [12] has used RSM to identify the ideal process parameters to produce thin shell plastic parts and has been consistent in maintaining the product quality. Lin et al. [13] has used RSM to deliberate the mechanical characteristic in 3 different types of composites materials.

Yung-Tsan Jou, Wen-Tsann Lin, Wei-Cheng Lee and Tsu-Ming Yeh,[14] have integrated the taguchi method with RSM they have done experiments on melt temperature, injection pressure, packing pressure and packing time and they have optimized the process to get an good quality of the molded component.

Changyu Shen, Lixia Wang, Wei Cao\& Li Qian [15] have conducted various experiments to investigate the effect of molding variables on sink mark using taguchi. Sokkalingam Rajalingam, Pandian Vasant, Cheng Seong Khe, Zulkifli Merican and Zeya [16] have worked on the response surface methodology to optimize the molding process by varying the parameters such as injection pressure, Holding pressure and filling time. Mathivanan, N. Parthasarathy [17] have worked on the reduction of the sink mark by using response surface regression modeling and genetic algorithm. Chorng-Jyh Tzeng a , Yung-Kuang Yang a , Ming-Hua Hsieh a \& Chun-Yuan Chen [18] have worked on the Adaptive Adjustment of Injection Molding Process for Mechanical Characteristics Using the Taguchi Method and Response Surface Methodology and the results shows these are effective tools to optimize the parameters in injection molding. Ko-Ta Chiang and Fu-Ping Chang [19] have used Response surface Methodology to reduce shrinkage by optimizing the injection molding parameters to reduce shrinkage on the final parts.

The researchers like Gyadari Ramsey, M.Yadi Reddy [21] have taken up study on the minimizing the Sinkmark on the molded parts which they have identified 3 process sets are taken for study and found So it can be concluded that to minimize sink marks only by using single gate and process parameters with Max.Injection Pressure of 180Mpa, Mold Temperature of 40c and Melt temperature 200c is better.

D. Mathivanan1, M. Nouby and R. Vidhya [20] they have done the work on the reduction of sink mark on the molded components in this the researchers have observed that the increased distance of RIB from the injection gate is increasing the sink. They have suggested while designing a part this has to be taken care for sink mark 
free molded parts and to improve the quality of the parts. Dieter P. Gruber a, Johannes Macher a, Dietmar Haba a, Gerald R. Berger b, Gernot Pacher a, Walter Friesenbichler [22] have carried out experiments to measure the Visual perceptibility of Sinkmark on injection molding.

Mohd Afiq harun, Shayfull Zamree, Abdul Rahim,Mohd Nasir MAT SAAD, Mohd Fathullah GHAZALI[23] has studied the effects of processing parameters and they have identified Acrylonitrile Butadiene Styrene (ABS) material molded parts Front panel housing for their study they have tried to reduce the warpage on the molded part and found out the most important factors which contribute to warpage through Design of experiment (DOE) with full factorial design and RSM used to reduce the warpage on the molded part. The noteworthy parameters that lead to warpage were identified from DOE analysis.

Park and Nguyen [24] carried out a study on the car fender-based injection molding process optimization their aim was to determine the relation between quality of the part and the energy consumed during molding process. AMI 2012 software which is used for simulation studies and Response surface methodology (RSM) was aligned with none dominated Sorting Genetic Algorithm II (NSGA II) as an optimization method in this study. The results proved to have improved the clamping force reduced $12 \%$ and the warpage was reduced $26.5 \%$ (from $4.349 \mathrm{~mm}$ to $3.194 \mathrm{~mm}$ ) after optimization.

Most of the researchers who have done the study on the warpage after molding have found it through various designs and process evaluation found that completely avoiding the warpage effect on the molded part is an uphill task in spite of using various techniques and methodology. The warpage can be minimized but not completely eliminated. The inclination of the warpage while cooling of the molded part after molding is bound to happen and it can be reduced by the fixing on cooling jigs to maintain the shape of the molded part but removing warpage in molding is an impossible task which is studied by the authors [25-28].

\section{DESIGN CONSIDERATION:}

In this study mold flow analysis is done in order to identify the link between the design constraints against the experimental approach

To integrate the design and process optimization in order to reduce the molding defects.

To find the cause and effects for various molding defects which is shown in fish bone Figure 1?

To evaluate the various design constraints using Design for Manufacturing approach.

To design the mold and simulate the injection molding process for ABS-LGMP220

To analyze the defects based on the complexity of mold

To predict the influence of process parameter and obtain the correlation by Central Composite

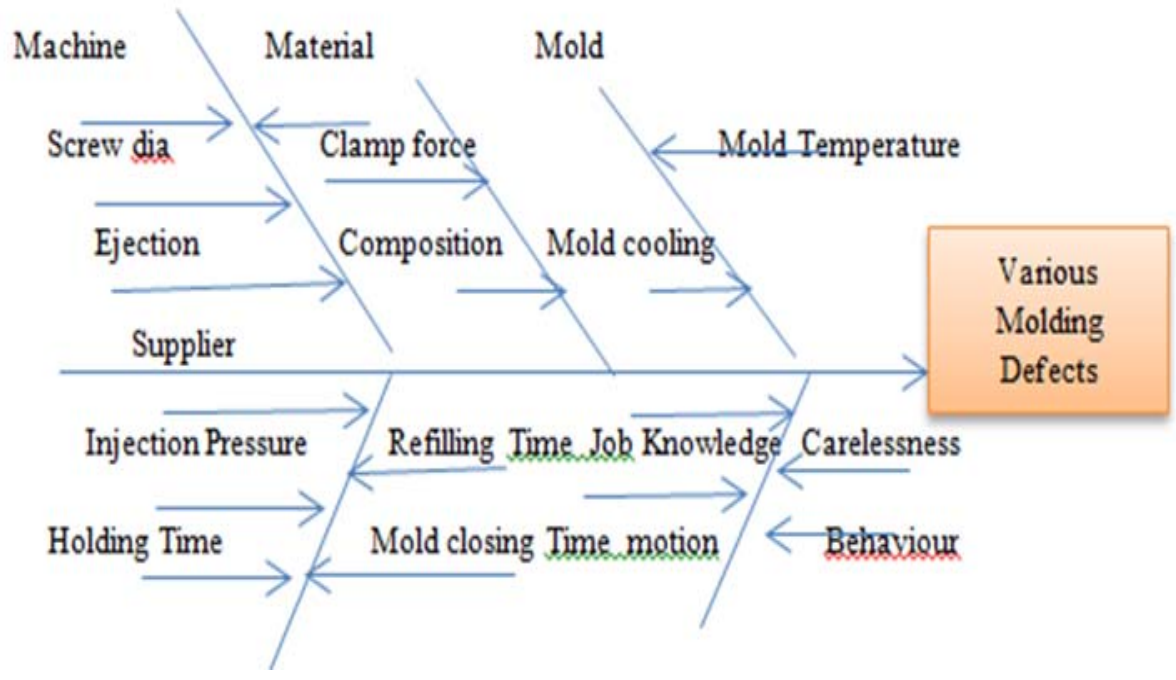

Fig 1: C\&E Diagram in Fish bone for molding defects 


\section{MATERIAL CONSIDERATION}

The material used in this study is ABS and the grade is LG MP 220 the mold design is made for ABS with shrinkage consideration for this material and the characteristics of the material is shown in Figure 1. The study takes the major consideration on the process parameters which basically affects the superiority of the product. ABS is considered for this part since this part for Plating requirement for automotive part supply and this material considered to be possessing high impact strength, dimensional stability. The basic optimum parameters are taken from the mold flow and experiment is done considering those parameters without compromising the quality requirement. This study is done to find out the output which is basically the cycle time

TABLE I

\begin{tabular}{|l|l|l|}
\hline Properties & Test Method & Value \\
\hline Specific Gravity & ASTM D792 & 1.05 \\
\hline Tensile Strength,3.2mm@yield & ASTM D638 & $450 \mathrm{~kg} / \mathrm{cm}^{2}$ \\
\hline Melt Flow Rate@220C/10kg & ASTM D1238 & $18 \mathrm{~g} / 10 \mathrm{Min}$ \\
\hline Molding Shrinkage(Flow),3.2mm & ASTM D955 & $0.4-0.7 \%$ \\
\hline Flexural strength,3.2MM & ASTMD790 & $760 \mathrm{Kg} / \mathrm{cm}^{2}$ \\
\hline Flexural Modulus,3.2MM & ASTM D790 & $25000 \mathrm{Kg} / \mathrm{cm}^{2}$ \\
\hline Tensile Elongation,3.2mm@Yield & ASTM D638 & $40 \%$ \\
\hline
\end{tabular}

\section{MACHINE USED}

The injection molding machine which is used is Engel -220T injection molding which is used is Engel -220T injection molding machine, where the locking force is 220T and the Maximum injection force (120-140 MPa) the shot size is .screw pressure time $(0.06 \mathrm{~s})$, and shot size is $300 \mathrm{Gms}$

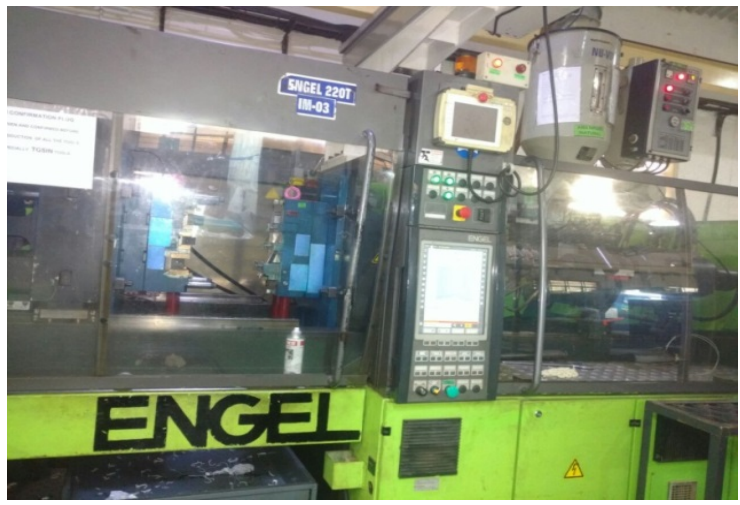

Fig 2a: Engel Injection Molding Machine

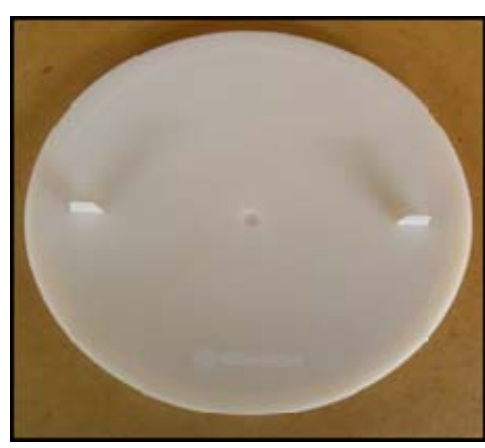

Fig 2b: Specimen

Temperature at flow front

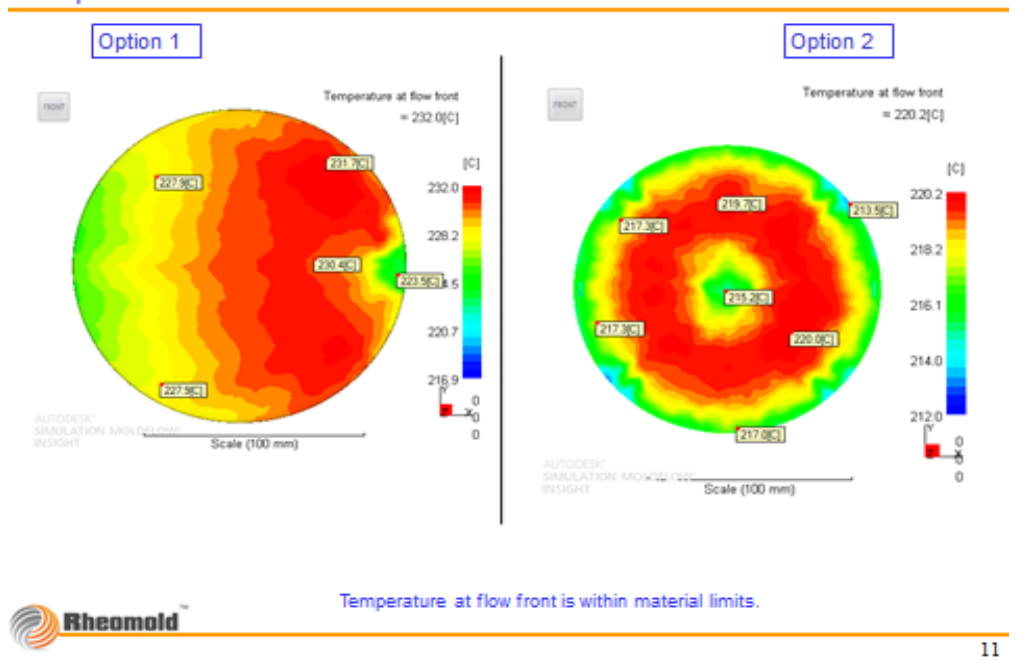

Fig.3 Temperature at Flow Front (GATE) 


\section{RESPONSE SuRface Methodology:}

This Response surface methodology approaches the solution where an practical and theoretical techniques are integrated basically to develop satisfactory functional relationship between the input parameter and the response $y$, Input parameters are symbolized by $x 1, x 2, \ldots, x k$. In this study we have taken up statistical modeling to build similarity between the response $y$ and independent variables

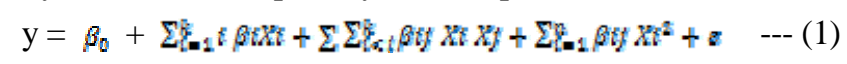

$\boldsymbol{x}=(x 1, x 2, \ldots, x k)_{-}, \boldsymbol{\beta} *=(\beta 1, \beta 2, \ldots, \beta k)_{-}$, and $\boldsymbol{B}$ is a symmetric matrix of order $k \times k$ whose $i$ th diagonal element is $\beta i i(i=1,2, \ldots, k)$, and its $(i, j)$ th off-diagonal element is $1 / 2 \beta i j\left(i, j=1,2, \ldots, k ; i_{-}=j\right)$.

The equation (1) is the mostly used second degree polynomial in RSM these are called as second order design. The evaluation of the following parameters Injection time(IT), Holding time(HT), refilling time(RT) and the mold closing time(MCT) and the output $\mathrm{Y}$ is cycle time(CT) experiments have been carried out using the above said variables.

A second-order design is used which provides a substantial improvement on the optimization process where a first order design will not give the results due to lack of fit.

The common method used in RSM is regression method we have used Minitab 17 for the RSM analysis with the central composite design(Face centered) in order to determine which regression will suit our data's. We have obtained R-sq and R-sq Adj for each of the model, Full Quadratic, Linear, Linear-Square and Linear-Interaction. Based on the the R-sq and R-sq Adj based on least square method the results are reported.

\section{INVESTIGATIONAL TECHNIQUE:}

Research has been done on ABS MP 220 LG raw material and 4 ideal process parameter which has been taken for the study and its experimental levels are studied. The parameters which are taken for our study are Injection time(IT), Holding time(HT), refilling time(RT) and mold closing time(MCT) and the output $\mathrm{Z}$ is cycle time(CT). Table 2 Gives the value of process parameter for experimental analysis here 3 different values has been taken into consideration to find out the suitable process and to get consistent part quality. Table 3 represents the experimental settings on Second order polynomial equations for Cycle time by varying the experiments with various settings.Table 5 represents the Polynomial model is done on independent variable based on practical experiments as well as the simulation and production experiments. RSM in this paper is done between different parameters and to find out the effect of these parameters on the output which is cycle time. With the parameters which are arrived are used and further developed in an second order polynomial.The machine used is Engel 220T is shown in Fig. 2a, part considered is Specimen mold which is shown in Fig 2b.The temperature in the gate area and the material flow pattern with temperature is shown in Fig.3. The footsteps involved in the response surface methodology is shown in Fig 6.The normal probability of the residual is presented in Fig 6.Profiles of surface generated plots as of a quadratic models during the optimization of input variables Fig.7.The effect of cycle time on the process parameters which has been selected for this study is revealed in Fig.8.The Augmented results of Minimum cycle time is understood in Fig.9

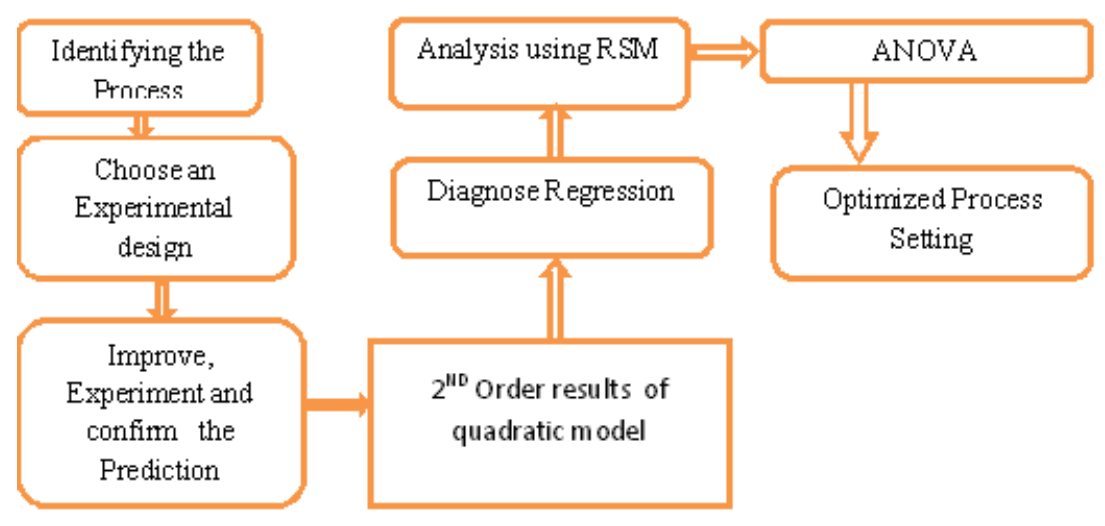

Fig 4: Process cycle 
TABLE II. Process Parameters for experimental analysis

\begin{tabular}{|l|l|l|l|l|}
\hline $\begin{array}{l}\text { Denot } \\
\text { ed }\end{array}$ & Process Parameter & $\begin{array}{l}\text { Stag } \\
\text { e 1 }\end{array}$ & $\begin{array}{l}\text { Stag } \\
\text { e 2 }\end{array}$ & $\begin{array}{l}\text { Stag } \\
\text { e 3 }\end{array}$ \\
\hline IT & $\begin{array}{l}\text { Injection } \\
\text { Time(Sec) }\end{array}$ & 18 & 19 & 20 \\
\hline HT & $\begin{array}{l}\text { Holding } \\
\text { Time(Sec) }\end{array}$ & 5 & 6 & 7 \\
\hline RT & $\begin{array}{l}\text { Refilling } \\
\text { Time(sec) }\end{array}$ & 28 & 29 & 30 \\
\hline MCT & $\begin{array}{l}\text { Mold Closing } \\
\text { Time(Sec) }\end{array}$ & 1.3 & 1.4 & 1.5 \\
\hline
\end{tabular}

TABLE III. Experimental settings for cycle time

\begin{tabular}{|c|c|c|c|c|c|}
\hline Exp.No & IT & HT & RT & MCT & CT \\
\hline 1 & 18 & 5 & 28 & 1.3 & 77.60 \\
\hline 2 & 19 & 5 & 28 & 1.3 & 78.35 \\
\hline 3 & 20 & 5 & 28 & 1.3 & 78.85 \\
\hline 4 & 18 & 6 & 29 & 1.3 & 77.96 \\
\hline 5 & 19 & 6 & 29 & 1.3 & 78.50 \\
\hline 6 & 20 & 6 & 29 & 1.3 & 78.24 \\
\hline 7 & 18 & 7 & 30 & 1.3 & 79.50 \\
\hline 8 & 19 & 7 & 30 & 1.3 & 80.15 \\
\hline 9 & 20 & 7 & 30 & 1.3 & 80.35 \\
\hline 10 & 18 & 5 & 28 & 1.4 & 77.90 \\
\hline 11 & 19 & 5 & 28 & 1.4 & 78.45 \\
\hline 12 & 20 & 5 & 28 & 1.4 & 78.75 \\
\hline 13 & 18 & 6 & 29 & 1.4 & 77.40 \\
\hline 14 & 19 & 6 & 29 & 1.4 & 78.60 \\
\hline 15 & 20 & 6 & 29 & 1.4 & 78.34 \\
\hline 16 & 18 & 7 & 30 & 1.4 & 79.70 \\
\hline 17 & 19 & 7 & 30 & 1.4 & 80.25 \\
\hline 18 & 20 & 7 & 30 & 1.4 & 80.50 \\
\hline 19 & 18 & 5 & 28 & 1.5 & 78.50 \\
\hline 20 & 19 & 5 & 28 & 1.5 & 78.65 \\
\hline 21 & 20 & 5 & 28 & 1.5 & 79.00 \\
\hline 22 & 18 & 6 & 28 & 1.5 & 78.30 \\
\hline 23 & 19 & 6 & 28 & 1.5 & 78.60 \\
\hline 24 & 20 & 6 & 28 & 1.5 & 78.25 \\
\hline 25 & 18 & 7 & 28 & 1.5 & 77.60 \\
\hline 26 & 19 & 7 & 28 & 1.5 & 78.35 \\
\hline 27 & 20 & 7 & 28 & 1.5 & 78.40 \\
\hline 28 & 18 & 6 & 30 & 1.3 & 78.40 \\
\hline 29 & 19 & 5 & 30 & 1.4 & 78.30 \\
\hline 30 & 20 & 7 & 30 & 1.5 & 80.60 \\
\hline 31 & 18 & 7 & 29 & 1.5 & 78.40 \\
\hline & & & & \\
\hline 19 & & \\
\hline
\end{tabular}




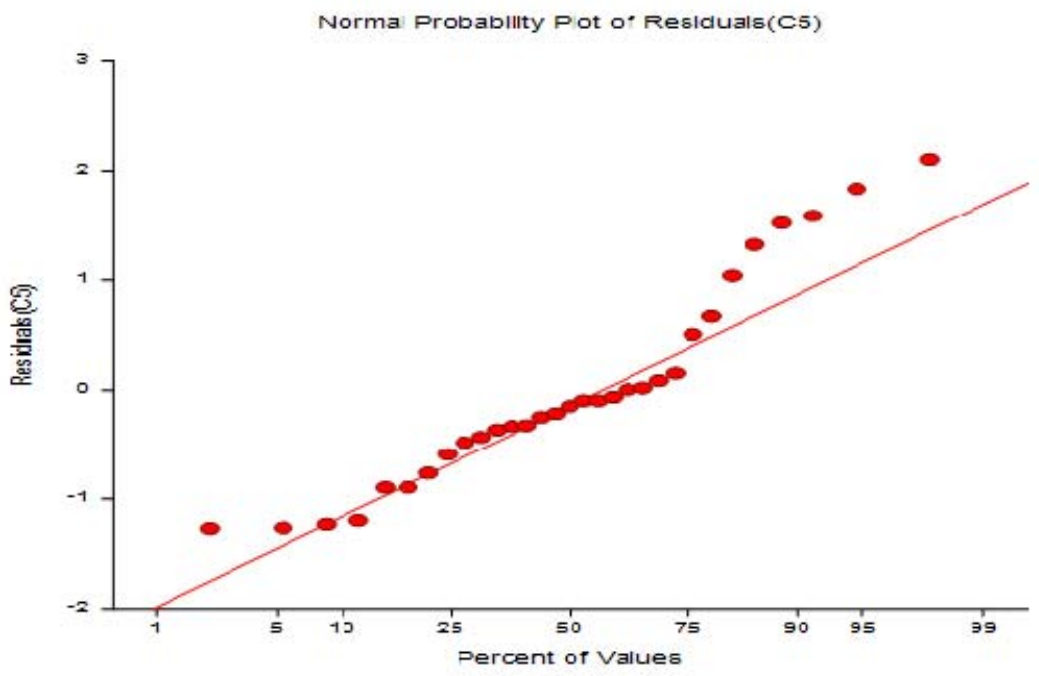

Fig 5: Represents the Residual of Cycle Time
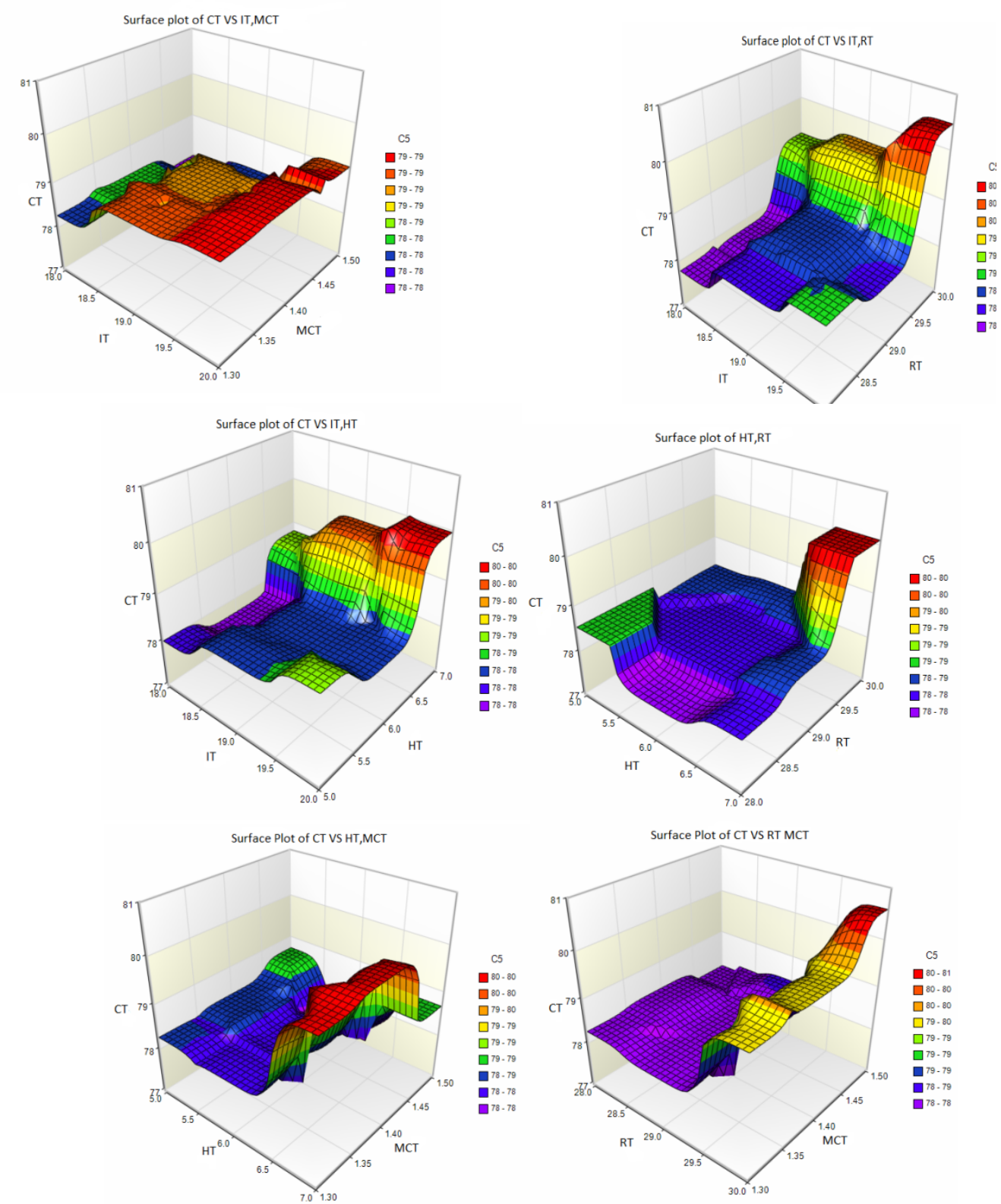


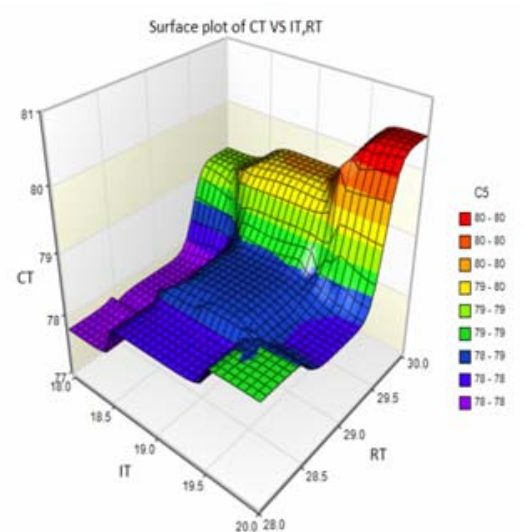

Fig6. Profiles of surface generated plots as of a quadratic models during the optimization of input variables

TABLE IV. Effect of process parameter on Cycle time

\begin{tabular}{|c|c|c|c|c|c|}
\hline Source & DF & Adj SS & Adj MS & F-Value & P-Value \\
\hline Model & 14 & 25.5444 & 1.82460 & 35.53 & 0.000 \\
\hline Linear & 4 & 14.0782 & 3.51954 & 68.53 & 0.000 \\
\hline IT & 1 & 2.1036 & 2.10357 & 40.96 & 0.000 \\
\hline HT & 1 & 0.1982 & 0.19825 & 3.86 & 0.067 \\
\hline RT & 1 & 1.0612 & 1.06118 & 20.66 & 0.000 \\
\hline MCT & 1 & 0.1542 & 0.15418 & 3.00 & 0.102 \\
\hline Square & 4 & 1.5790 & 0.39475 & 7.69 & 0.001 \\
\hline IT*IT & 1 & 0.2781 & 0.27815 & 5.42 & 0.033 \\
\hline HT*HT & 1 & 0.7700 & 0.76998 & 14.99 & 0.001 \\
\hline RT*RT & 1 & 0.0001 & 0.00010 & 0.00 & 0.966 \\
\hline MCT*MCT & 1 & 0.0171 & 0.01715 & 0.33 & 0.571 \\
\hline 2 Way Interaction & 6 & 3.3298 & 0.55496 & 10.81 & 0.000 \\
\hline IT*HT & 1 & 0.0215 & 0.02152 & 0.42 & 0.527 \\
\hline IT*RT & 1 & 0.0240 & 0.02405 & 0.47 & 0.504 \\
\hline IT*MCT & 1 & 0.0171 & 0.01708 & 0.33 & 0.572 \\
\hline HT*RT & 1 & 0.7794 & 0.77944 & 0.001 & \\
\hline HT*MCT & 1 & 0.0031 & 0.00312 & 0.809 & \\
\hline RT*MCT & 1 & 0.0078 & 0.00779 & 0.702 & \\
\hline ERROR & 16 & 0.8217 & 0.05136 & & \\
\hline TOTAL & 30 & 26.3661 & & & \\
\hline
\end{tabular}




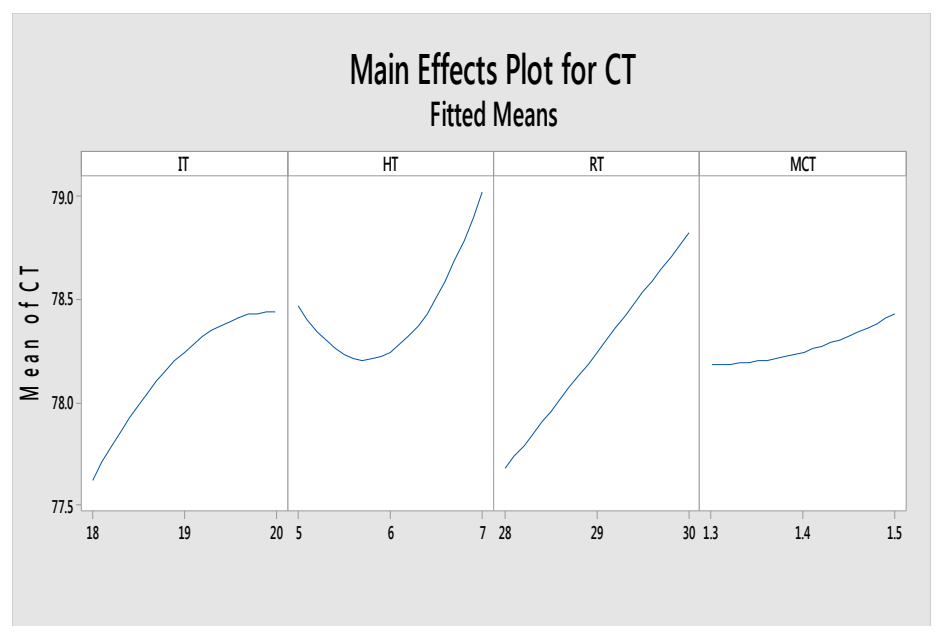

Fig7: Augmented results of Minimum cycle time

\section{VII.CONCLUSION AND RESULTS:}

In Injection molding process settings are directly related to the manufacturing cost. In olden days most of the parameter settings are always done on experience of the operators in the field which leads to process parameters not optimized which affects directly the quality of the molded part and we will not able to reproduce the same level of quality continuously. In order to get the repeatability of the molded parts there has been many techniques used one of it is RSM.We have seen in this the usage of RSM on ABS(LG mp 220) on injection molding machine apart from that we have also seen the impact of process parameters and also created an quadratic model for cycle time analysis based on various process changes and the results are Based on the ANOVA table it is shown that prediction of the cycle time(CT) through quadratic model (CT) with 96.88\%.Confident interval.

- Surface plots and Contour plots have been plotted for studying combined effect of two factors while keeping other factor at their least-values.

- The parameters which have identified for the experiment proves that effect of Injection time, Holding time and mold closing time contribute in the range of $86.46 \%, 2.86 \%$ and $5.45 \%$ respectively and the refilling time doesn't have a say on the total variability of model.

- The ANOVA also proves that the collaboration of parameters between them and the squares doesn't play any part in the determination of cycle time.

- It has been found that the following process parameter with a setting of Injection Time (18 Sec),Holding Time (5sec),Refilling time (28Sec) and Mold closing time (1.3 Sec) is the ideal condition for Cycle time.

\section{References}

[1]Awang Bono, J Sulaiman and S Rajalingam, Analysis of Optimal Injection Moulding Process Parameters for Thin-Shell Plastic Product using Response Surface Methodology, Journal of Applied Sciences, 2014, 14, 3192-3201.

[2]Ko-Ta Chiang \& Fu-Ping Chang, Analysis of Shrinkage and Warpage in an Injection-Molded part With a Thin Shell Feature using the Response surface Methodology, Int J Adv Manuf Technol, 2007, 35,468-479.

[3]Application of RSM to Optimize Molding Conditions for Minimizing Shrinkage in Thermoplastic Processing, S. M. Nasir, K. A. Ismail1,b and Z. Shayfull1, Key Engineering Materials Submitted: 2016-03-11,ISSN: 1662-9795, Vol. 700, pp 12-21.

[4]Integrating the Taguchi Method and Response Surface Methodology for Process Parameter Optimization of the Injection Molding, YungTsan Jou, Wen-Tsann Lin, Wei-Cheng Lee and Tsu-Ming Yeh [4] Appl. Math. Inf. Sci. 8, No. 3, 1277-1285 (2014)

[5]Analysis of shrinkage and warpage in an injection-molded part with a thin shell feature using the response surface methodology, Ko-Ta Chiang \& Fu-Ping Chang, Int J Adv Manuf Technol (2007) 35:468-479, DOI 10.1007/s00170-006-0739-4

[6]Analysis and modeling of effective parameters for dimension shrinkage variation of injection molded part with thin shell feature using response surface methodology Chih-Cherng Chen \& Pao-Lin Su \& Yan-Cherng Lin, Int J Adv Manuf Technol (2009) 45:1087-1095.

[7]Ozcelik B, Erzumlu T (2005) Determination of effecting dimensional parameters on warpage of thin shell plastic parts using integrated response surface method and genetic algorithm. Int Common Heat Mass Transf 32:1085-1094.

[8]Kurtaran H, Ozcelik B, Erzurumlu T (2005) Warpage optimization of a bus ceiling lamp base using neural network model and genetic algorithm. J Mater Process Technol 169:314-319

[9]K. M. B. Jansen, D. J. V. A. N. Dijk, and M. H. Husselman: Polym. Eng. Sci. Vol. 35 (1998),p. 838-846.

[10] Long W, Kit-lun Y, Sun-pui N, Joanne Y, Kang-hoi K (2012) Parametric design and process parameter optimization for bra cup molding via response surface methodology. Expert Systems with Applications 39:162-171.

[11] Mathivanan D, Parthasarathy NS (2009) Prediction of sink depths using non-linear modeling of injection molding variables. International Journal of Advanced Manufacturing Technology 43:654-663

[12] Chuang MT, Yang YK, Hsiao YH (2009) modeling and optimization of injection molding process parameters for thin-shell plastic parts. Polymer-Plastics Technology and Engineering 48:745-753.

[13] Lin SS, Lin JC, Yang YK (2010) Optimization of mechanical characteristics of short glass fiber and polytetrafluoroethylene reinforced polycarbonate composites via D-optimal mixture design. Polymer-Plastics Technology and Engineering 49:195-203. 
[14] Integrating the Taguchi Method and Response Surface Methodology for Process Parameter Optimization of the Injection Molding Yung-Tsan Jou1, Wen-Tsann Lin, Wei-Cheng Lee and Tsu-Ming Yeh, Appl. Math. Inf. Sci.8, No. 3, 1277-1285 (2014).

[15] Investigation of the Effect of Molding Variables on Sink Marks of Plastic Injection Molded Parts Using Taguchi DOE Technique, Changyu, Lixia Wang, Wei Cao \& Li Qian, Pages 219-225 | Published online: 22 Mar 2007, http://dx.doi.org/10.1080/03602550601152887 